\title{
Prémios de teatro regressam à Grécia muitos séculos depois
}

\author{
Maria Helena Serôdio
}
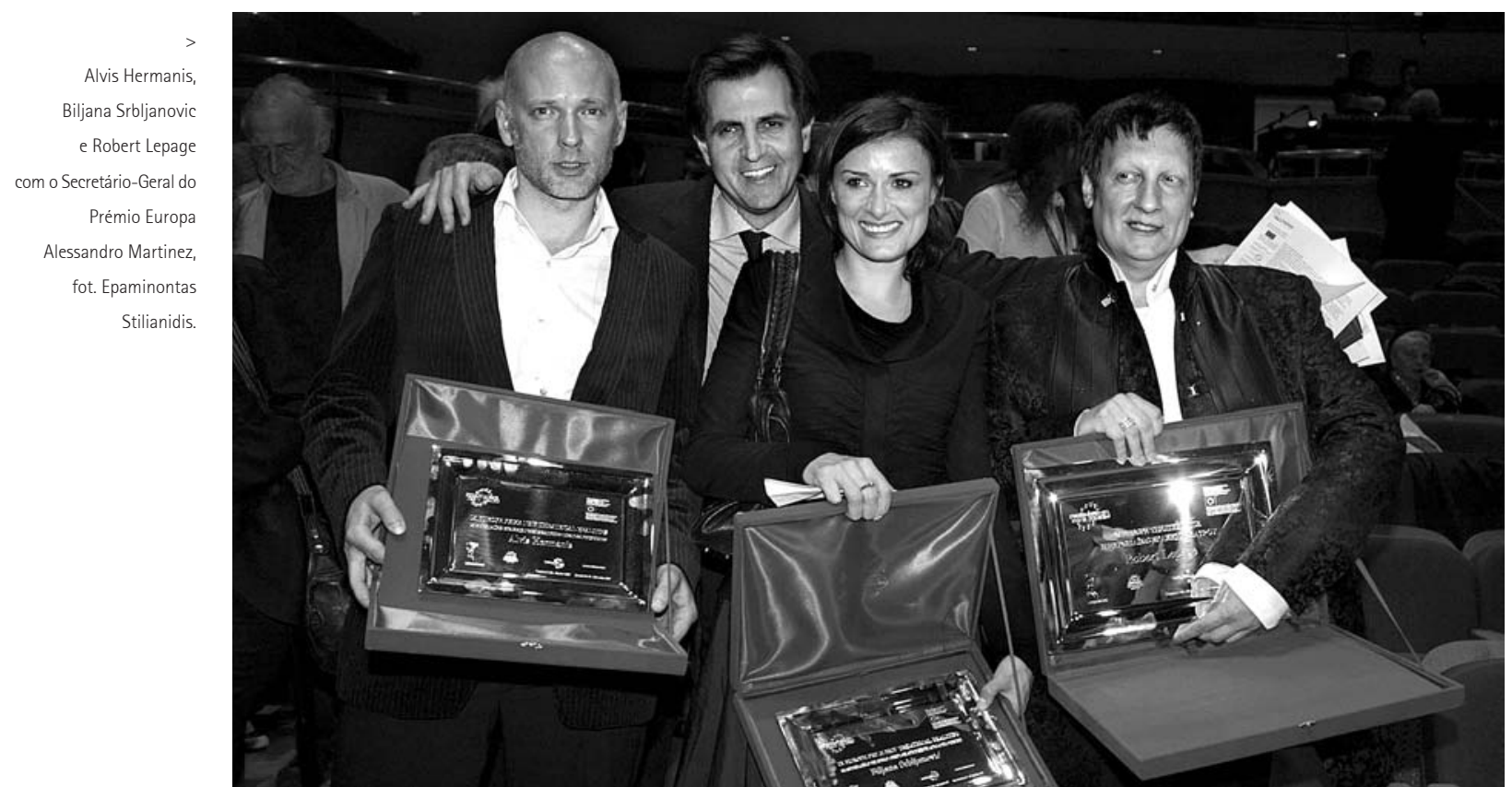

Referindo-se a fazedores de teatro, Pier Paolo Pasolini terá um dia declarado: "não somos muitos, mas viemos todos da Grécia".

0 mesmo se poderá dizer dos prémios de teatro que, desde as festividades dedicadas a Dioniso na Atenas do século V a.C. - a Dionisia Urbana -, eram anualmente atribuídos aos autores de tragédias, implicando a distinção de um $1 .{ }^{\circ}, 2{ }^{\circ}$ e $3 .^{\circ}$ lugar em cada edição. E foi assim que, segundo parece, Ésquilo terá recebido 13 vezes o prémio, Euripedes 4 e Sófocles, de longe o mais galardoado, 18 (para não falar das muitas outras vezes que recolheu o $2 .{ }^{\circ}$ lugar, mas nunca o $3 .{ }^{\circ}$ ).

Estas eram as circunstâncias maiores recordadas por todos os que em Tessalonica recentemente se reuniram para mais uma edição festiva - e exigente do ponto de vista artístico - do Prémio Europa para o teatro.

Tributo aos criadores de teatro

Criado em 1987, o Prémio Europa para o teatro teve a sua

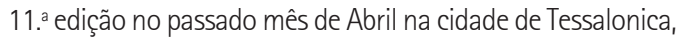
no norte da Grécia, depois de nove das suas edições terem tido por palco Taormina, e o ano passado a cerimónia e as habituais actividades paralelas - entrevistas a premiados, colóquios, testemunhos e apreciações críticas, bem como apresentação de espectáculos - terem decorrido em Milão.
Envolvendo como instituições apoiantes a União dos Teatros da Europa e a Convenção Teatral Europeia, o Prémio Europa conta também - como organismos associados com a Associação Internacional de Críticos de Teatro e o Instituto Internacional do Teatro do Mediterrâneo, tendo este ano registado ainda o apoio do Teatro Nacional da Grécia do Norte e do município de Tessalonica.

0 galardão de 2007 foi ex-aequo para Robert Lepage e Peter Zadek, configurando uma situação nova, uma vez que as edições anteriores tinham distinguindo um só criador, respectivamente, Ariane Mnouchkine, Peter Brook, Giorgio Strehler, Heiner Müller, Robert Wilson, Luca Ronconi, Pina Bausch, Lev Dodin, Michel Piccoli e Harold Pinter. E, em minha opinião, terá sido, porventura, essa uma das razões - ainda que não declarada - para que o encenador alemão, pretextando estar ocupado com os ensaios da peça Como quiserdes, de Shakespeare, não tivesse comparecido, o que não só motivou que fossem suspensas as sessões dedicadas à sua obra, como também que não Ihe fosse atribuído o galardão (uma placa em prata) e o prémio pecuniário (trinta mil euros, uma vez que repartia a totalidade com o encenador do Quebeque), dado que as regras do Prémio impõem esse compromisso presencial. Apesar de uma azeda troca de cartas entre o encenador e o júri, a restrição manteve-se, mas o espectáculo com que 


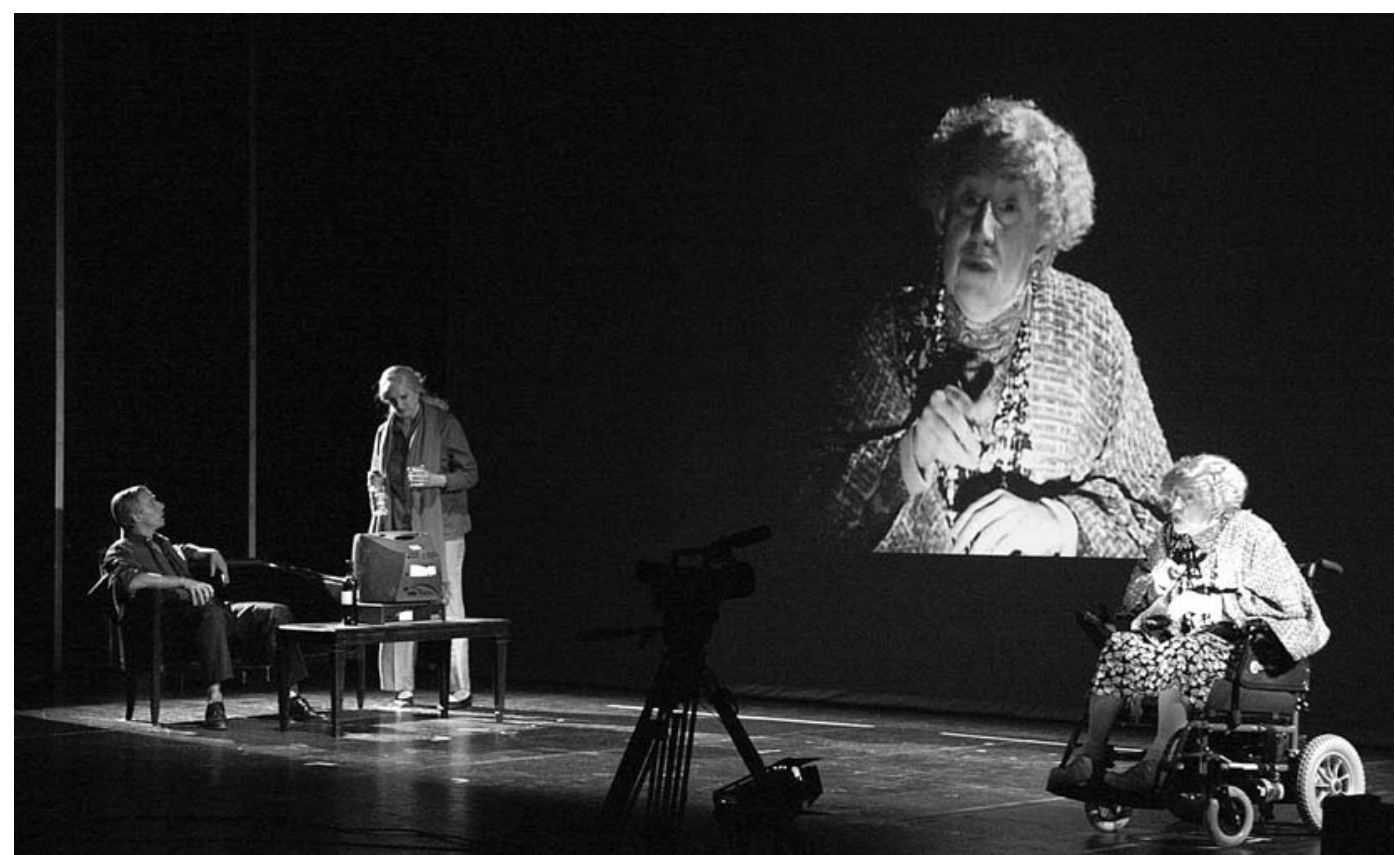

fechou esta edição do Prémio - Peer Gynt, pelo Berliner Ensemble dirigido por Zadek - acabou por concitar de tal modo o entusiasmo do público que no final a sala distinguia com uma ovação acalorada o espectáculo, o colectivo e o seu encenador.

Se um dos requisitos do Prémio é justamente o de se apresentarem espectáculos dos premiados, no caso de Robert Lepage, a sua produtora "dificilmente" poderia comprometer-se a fazê-lo - na medida em que programa com uma antecedência de mais de um ano cada produção -, pelo que o recurso foi uma colagem de algumas cenas de diferentes espectáculos que estão em cartaz em vários paises, o que fez chegar àquela cidade do Norte da Grécia alguns dos actores que um pouco por vários lugares da Europa estavam a apresentar produções da companhia de Lepage, a Ex-Machina. Com excertos de Projecto Andersen, Lipsynch (Sincronia de lábios) e Far Side of the Moon (Lado distante da lua), o espectáculo durou cerca de 45 minutos, e pôde, de forma eloquente, demonstrar a verdade do epíteto escolhido para enquadrar os muitos testemunhos sobre a sua obra: "0 visionário do Quebeque".

0 que Georges Banu sublinhou na cerimónia de atribuição do Prémio Europa, que ocorreu no dia 29 de Abril à noite, foi a evidência de que esta distinção - visando destacar um artista (ou uma instituição) que tenha contribuido "para o conhecimento e a compreensão mútua entre nações" -, não restringe o universo teatral, sobre que se debruça, a uma acepção meramente geográfica, antes celebra o que se exerce nesse espaço cultural e de forma positiva marca uma Europa do espírito, bem como uma incontestada excelência artística. Até porque dificilmente se entenderia o teatro de hoje sem a contribuição decisiva de criadores do outro lado do Atlântico como Robert Wilson ou Robert Lepage, por mais discutiveis que possam ser algumas das suas propostas artísticas.

\section{As novas realidades do teatro}

Por ocasião da 3. edição do Prémio Europa foi criado um prémio que pudesse destacar novos valores para lá da consagração dos artistas maiores, pelo que neste ano de 2007 se cumpriu a sua 9. atribuição, recaindo sobre a jovem dramaturga sérvia Biljana Srbljanovic e sobre o encenador e actor (e actualmente director do Novo Teatro de Riga) Alvis Hermanis, da Letónia, que entre si repartiram a quantia de vinte mil euros.

De Biljana Srbljanovic (n. 1970) pudemos já ver em Portugal duas das suas peças - Histórias de família e América (a partir de Amerika, de Franz Kafka) respectivamente em 2003 e 2005, em produções da APA - Actores Produtores Associados, ambas encenadas por 

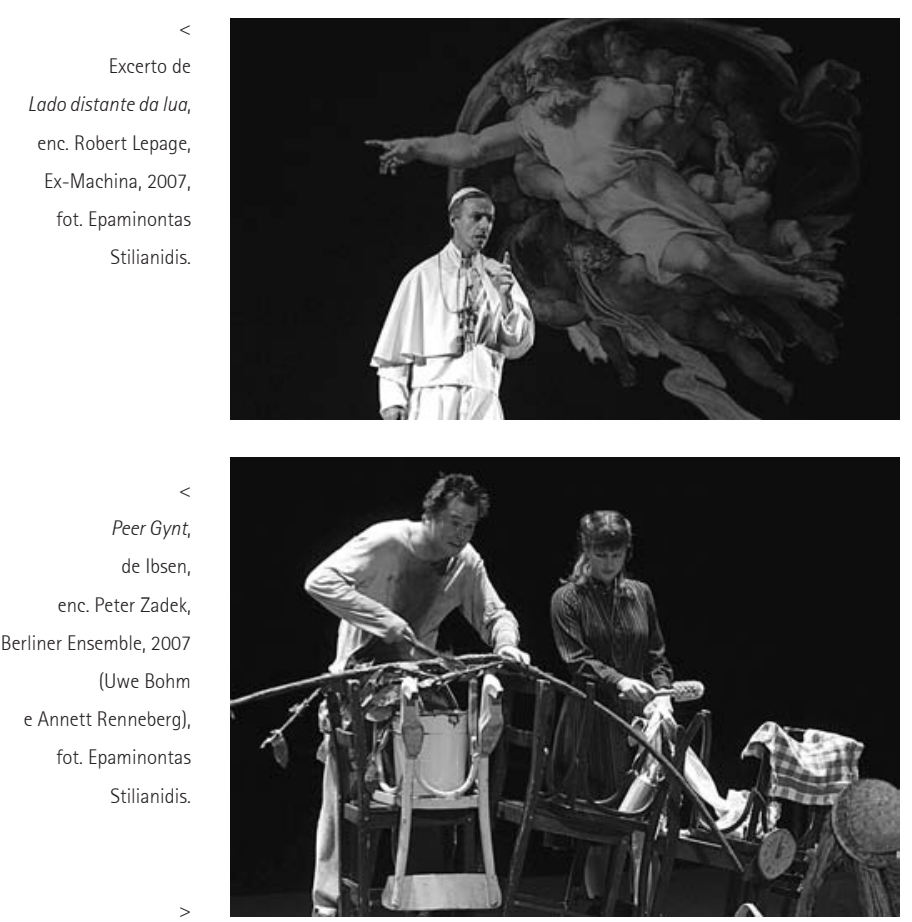

Peer Gynt,

de lbsen,

enc. Peter Zadek,

Berliner Ensemble, 2007

(Angela Winkler

e Uwe Bohm)

fot. Epaminontas

Stilianidis
Manuel Wiborg. Em Tessalonica, no contexto das sessões sobre a obra dos premiados, foi Thomas Ostermeier quem mais se deteve a falar da autora com quem vem

estabelecendo uma relação artística electiva na Schaubühne, teatro que dirige e em cuja programação se destacam as obras mais marcantes da dramaturgia contemporânea.

Sublinhou na sua intervenção a curiosa convergência do local e do universal na dramaturgia de Biljana, por um lado focando a realidade sérvia (Trilogia de Belgrado e A queda), mas, por outro lado, abrangendo realidades e problemas de ordem mundial. Chamado a confrontar as suas peças com a dos dramaturgos anglo-saxónicos que mais tem encenado, Ostermeier referiu o modo menos violento (em palavras e acções) que marca a diferença das ficções dramáticas de Biljana, bem como uma especial atenção às questões da identidade de um país (com a consequente preocupação com a emigração e os problemas da dissidência). Demorou-se ainda na específica criação do espectáculo Supermercado que resultou de uma encomenda da Schaubühne. Duas questões curiosas prendiam-se ao desafio que tinha lançado à dramaturga sérvia: a de escrever sobre questões sérias mas recorrendo ao cómico, uma vez que, como afirmou o encenador, os actores da Schaubühne são melhores como actores cómicos. 0 espectáculo que resultou desta convergência artística apresentou-se em Berlim, circulou pela França e pela Áustria, mas entretanto já saiu de cartaz. Aparentemente o projecto concitou algum trabalho de análise de conteúdos e formas das telenovelas de todo o mundo e pretendeu parodiar essa "gramática" artística, ao mesmo tempo que apresentava - ironicamente - o fascínio pelo brilho da cultura pop de hoje, não the faltando, porém, um núcleo trágico no tecido dramatúrgico.

Quanto a Hermanis, se inicialmente se destacou pelas suas inspiradas encenações de clássicos como Gogol (0 inspector-geral), ou Arbuzov (Meu pobre Marat), a sua opção vem ultimamente recaindo no seu papel de autor/encenador com uma agenda teatral muito própria. De facto, invocando a necessidade de fazer entrar no teatro as emoções, é sobre a vida quotidiana no seu lado mais

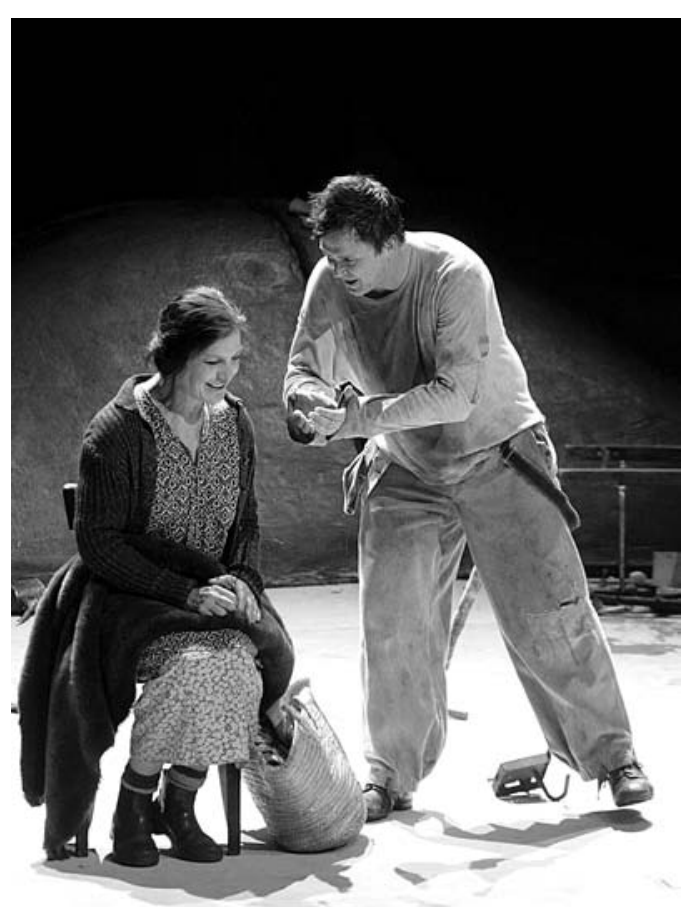

privado e de memórias pessoais que focaliza a sua atenção, promovendo entre os seus actores o gosto da observação dos outros - nas relações interpessoais e nos gestos diários de uma vida vulgar -, o que, de forma assumida, relembra os preceitos de Zola e Antoine. É claramente um nostálgico que diz preferir o passado a um futuro que não lhe desperta qualquer curiosidade ou entusiasmo, ao mesmo tempo que olha com alguma compaixão para os constrangimentos da vida dos mais simples ou o peso das recordações da infância que simultaneamente convocam um sentimento de saudade e de penosa lembrança de desentendimentos familiares.

De Hermanis foi possivel ver em Tessalonica duas peças que apresentavam características bastante diversas: Vida longa e Pais. E, todavia, uma temática forte os unia, como, de resto, se sentiu em praticamente todos os espectáculos que foram apresentados no contexto deste Prémio: a atenção ao envelhecimento e às imposições que o tempo vai fazendo pesar na vida de cada um.

\section{Variações sobre uma temática}

Interrogado sobre a evidência de que os espectáculos apresentados nesta 11. edição do Prémio Europa insistiam na representação dos problemas da velhice, Thomas Ostermeier admitiu que os artistas jovens reconhecem hoje que já não é tão importante falarem de si próprios, preferindo antes olhar à sua volta, atentos a alguns dos problemas sociais mais candentes. Entre eles figura, na sua opinião, o colapso da família e a marginalização dos velhos, com o que isso vem acarretando de condição trágica e de sentimento de culpa.

No caso de Biljana, o espectáculo Gafanhotos(Locusts), apresentado pelo Teatro Dramático Jugoslavo com encenação de Dejan Mijac, consistia numa sequência de cenas breves em que se confrontavam - no seio da família, entre vizinhos ou em situações de engate - uma pessoa mais velha ou mesmo idosa com gente mais jovem.

Desdobrando-se talvez por demasiados "casos exemplares" (no sentido de mais usuais, mas não menos dramáticos) 


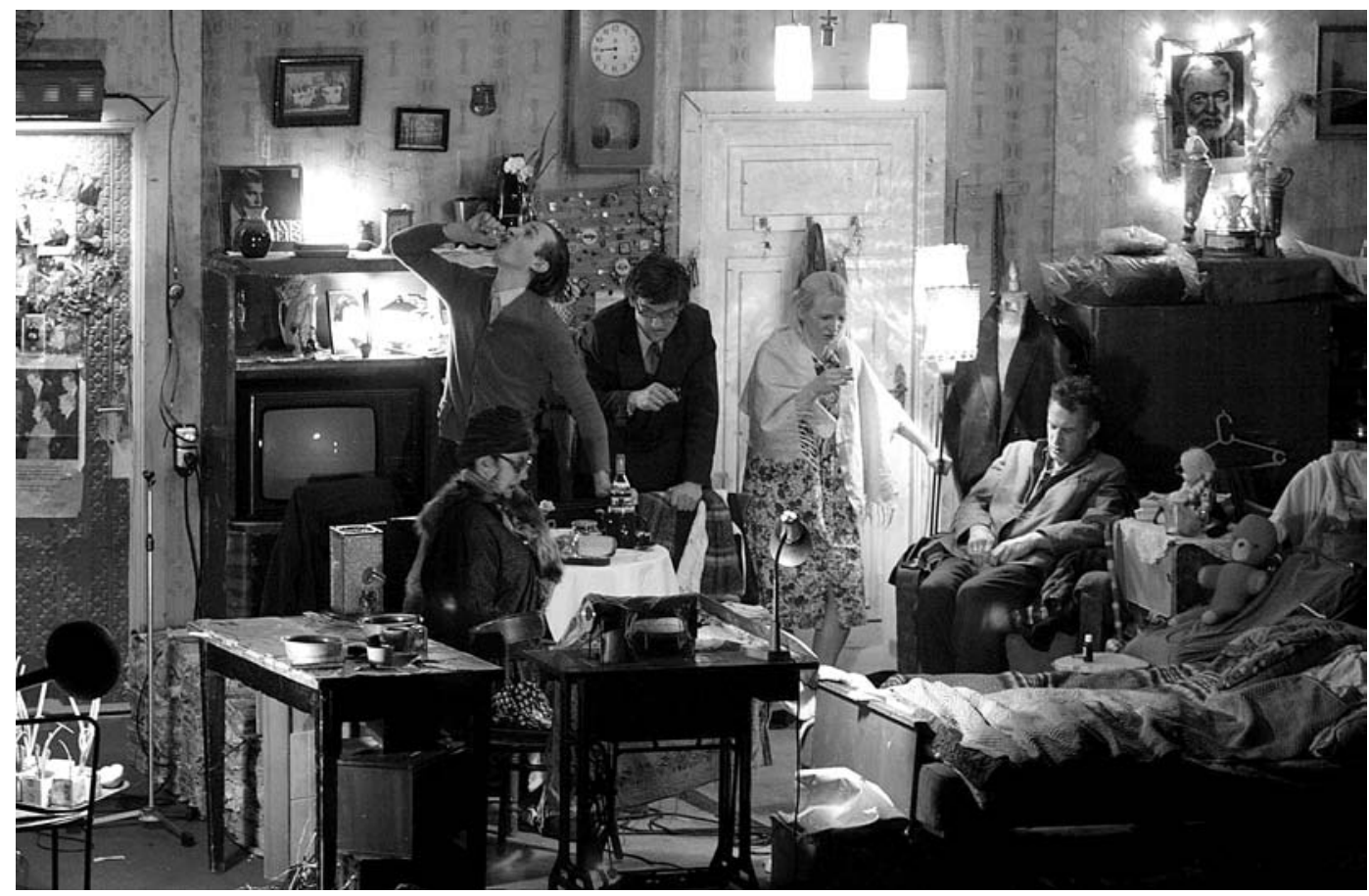

e por personagens tratadas com alguma superficialidade (rondando por vezes o estereótipo), o texto não deixava de ser uma denúncia feroz do egoismo mais cruel e da intolerância mais azeda relativamente a pais, mães ou ou ex-colegas a que assistimos hoje em dia um pouco por toda a parte. Com uma direcção que talvez não acompanhasse com igual desenvoltura a ágil carpintaria teatral do texto, o espectáculo criou, todavia, três situações cénicas de uma confrangedora aflição: o intelectual competente que, na transição política que ocorreu, se vê injustamente esquecido se não mesmo excluído de qualquer reconhecimento, o da mãe que quase é expulsa de casa da filha, porque comenta o seu azedume despropositado, e um filho que concebe (e executa) o plano de abandonar o pai com Allzheimer à beira de uma auto-estrada sem nenhum elemento de identificação (para que alguma instituição pública o recolhesse).

No caso de Hermanis, foram dois os espectáculos a que assistimos. No caso de Vida longa, levado à cena pelo Novo Teatro de Riga com encenação do autor, tratava-se de um espectáculo concebido para ser visto de muito perto (não mais do que sete filas), o que não aconteceu no auditório vasto do Teatro Nacional da Grécia do Norte, razão pela qual se facultavam binóculos aos espectadores para que pudessem observar os mínimos pormenores do espaço e da acção. Em palco estavam 5 actores (dois casais envelhecidos e um homem aparentemente mais jovem), representando o que poderia ser uma vivência de vizinhos, cada um com um minúsculo quarto, mas partilhando a cozinha e casa de banho. Os três aspectos mais salientes deste espectáculo eram, visivelmente, a concepção cenográfica (de uma obsessiva acumulação de elementos "reais" do quotidiano mais vulgar e de perfil claramente antiquado), o excepcional trabalho de composição das figuras por parte dos actores, e a minuciosa representação de um dia de vida repartido entre o ridículo de algumas ocupações e uma visão compadecida das fraquezas humanas nas condições limitativas em que viviam aquelas figuras. Assim, o cenário era composto por uma caixa rectangular - a toda a largura do palco e perto da boca de cena -, de texto baixo, onde se desenhavam três assoalhadas diminutas ao centro (imaginando-se divisórias entre elas) e na extremidade da direita uma cozinha quase primitiva, enquanto na esquerda surgia uma casa de banho rudimentar. Todas as divisões tinham uma porta ao fundo por onde entravam e saiam as figuras nos seus afazeres normais. 0 trabalho dos actores - muito jovens e sem qualquer maquilhagem -, exigia uma composição gestual e mímica extraordinárias, o que cumpriam de forma brilhante. Praticamente sem palavras (apenas uma canção ou pouco mais), o espectáculo descrevia as manias e tiques de cada um, implicando - para quem soubesse reconhecer em alguns dos pormenores na evocação do espaço e nas formas de comportamento - que um dos casais seria da Letónia, outro da Rússia, sendo o jovem solteiro um eventual nostálgico das SS alemães. Dirigido às recordações do que poderia ter sido o tempo dos nossos avós (ou bisavós, no caso de espectadores mais jovens), o espectáculo era uma primorosa exposição de um teatro que quer reintroduzir os sentimentos de reconhecimento do quotidiano e do interesse pelo humano (nas suas vivências mais precárias), capaz de suscitar o enternecimento perante tais visões da vida da gente vulgar.

O segundo espectáculo de Hermanis - Pais apresentado no auditório do antigo mosteiro dos Lazaristas por uma companhia suiça (Schauspielhaus de Zurique) com encenação do próprio autor, compunha-se de três monólogos de homens que iam desfiando recordações das suas vidas desde muito pequenos. De novo a tónica era nas relações familiares e na recordação do envelhecimento dos pais, mas a concepção cenográfica era ostensivamente construída por uma exposição de sucessivas telas que representavam, primeiro o lugar em que cada um trabalhava (e dois deles eram actores, pelo que se mostravam os camarins), e depois várias pinturas dos pais em momentos diferentes da vida. 0 espectáculo orientava-se para uma progressiva caracterização (por maquilhagem) dos actores em cena, até chegarem à idade de serem eles próprios 
Srbljanovic

enc. Dejan Mijac,

Teatro Dramático

Jugoslavo, 2007,

fot. Epaminontas

Stilianidis

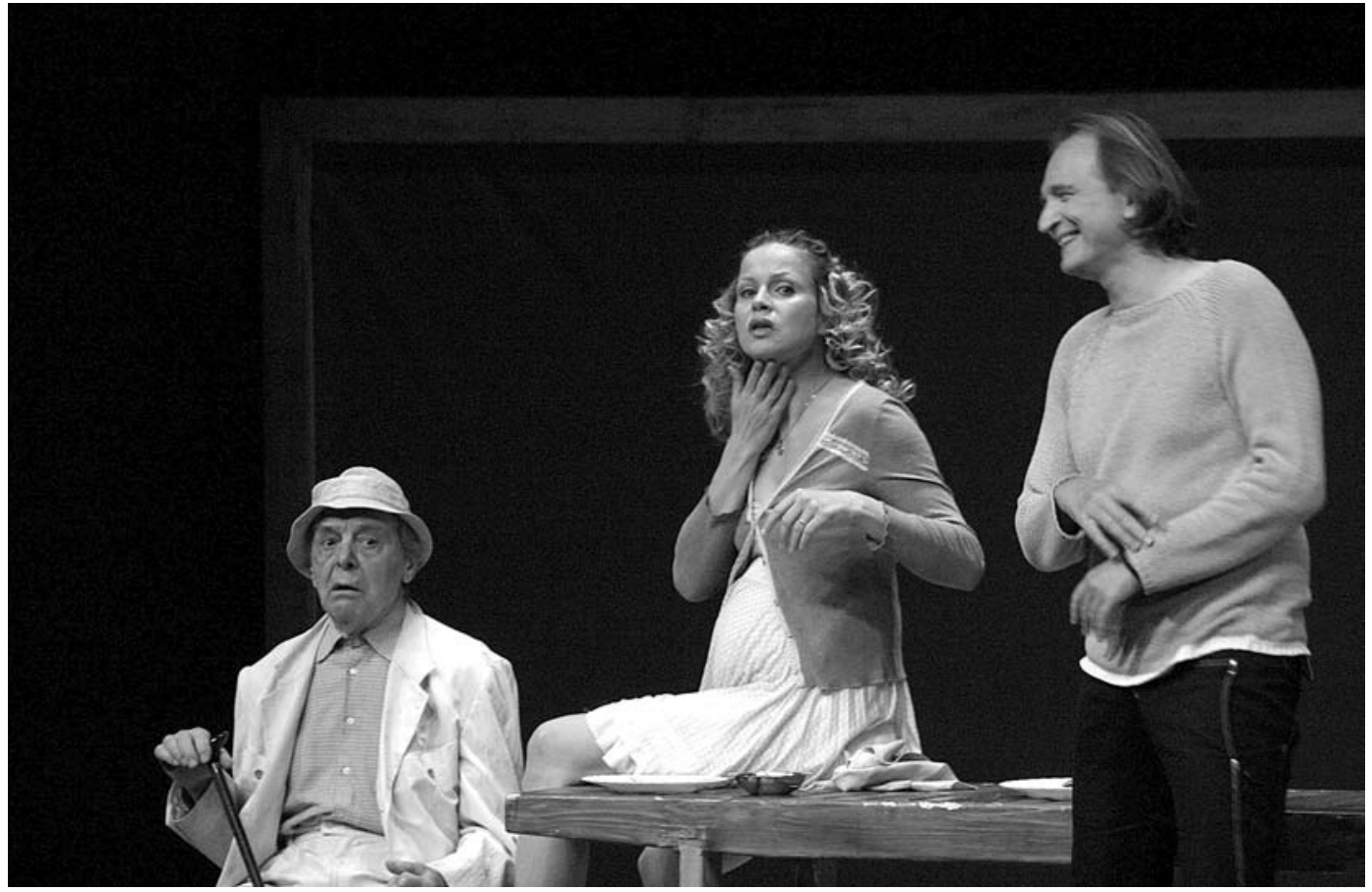

avós. Apesar do aspecto envolvente de algumas das

Pais,

texto e enc. de

Alvis Hermanis,

Schauspielhaus Zürich,

2007,

fot. Epaminontas

Stilianidis.

narrativas relatadas em directo para o público, o espectáculo revelou-se algo repetitivo, carecendo de uma melhor selecção dos materiais narrativos e, eventualmente, alguma lógica que reunisse aquelas figuras em cena.

Da selecção que Robert Lepage apresentou destacaria a simplicidade de meios com que encenou $A$ sombra, do Projecto Andersen (com uma simples lâmpada na mão que colocava à sua frente - projectando a sombra e o seu movimento no telão do fundo - ou atrás - anulando a visibilidade da figura), bem como as cenas que envolviam a representação da velhice, da afasia e da dificuldade da memória (aqui numa magistral interpretação de um actor - na figura de uma velha que lembraria a célebre Mrs. Marple, de Agatha Christie). Uma "revelação" relativamente a um pormenor do tecto da Capela Sistina (a concha em que está Deus rodeado de querubins coincide "rigorosamente" com o cérebro em radiografia de perfil) e uma cena simples de um corpo que se movimenta no chão, mas que uma câmara projecta no telão ao fundo fazendo parecer que se movimenta numa parede, foram outros dois materiais que identificamos bem nos processos mais usuais do seu teatro: o assombro de revelações surpreendentes e o gosto pelo lúdico.

Quanto ao espectáculo com que mais vibrou o público em Tessalonica - Peer Gynt, de Ibsen, que Peter Zadek encenou no Berliner Ensemble - foi, sem dúvida alguma, uma admirável criação. Usava um cenário "limpo": chão branco a toda a largura do palco, deixando a parte posterior da caixa de palco em negro, o que Ihe acrescentava profundidade e permitia moldura expressiva para um ou outro quadro. 0 trabalho excelente do actor Uwe Bohm no papel principal (ao lado de Ângela Winkler na figura da mãe), a invenção engraçadíssima dos "trolls" como um grupo de foliões de aspecto diverso (alguns com máscaras) entre imagens carnavalescas e apontamentos de bestiário, e a comicidade com que se representou a cena dos árabes, entre tantos outros momentos de teatro na sua expressão mais poderosa, comprovavam a solidez de um projecto

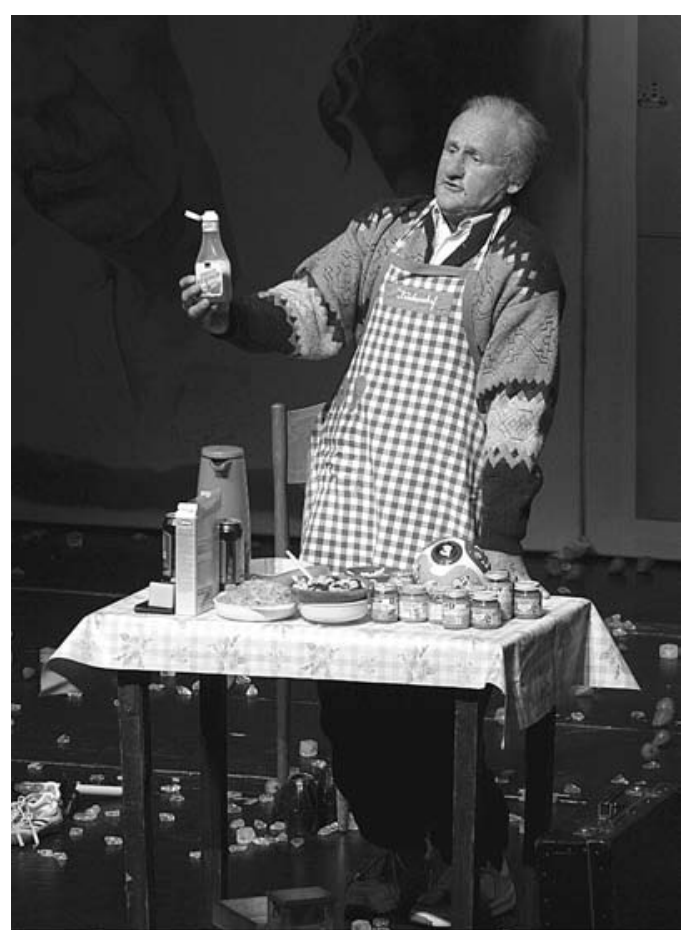

cénico que recriou, com uma enorme largueza de intenções e cambiantes, um percurso de aprendizagem de vida que nos tocava profundamente. Sem efeitos especiais, sem acumulação de elementos cenográficos, com uma imensa sobriedade de adereços (quase só cadeiras, uma roda de bicicleta, mesas, um telão onde se introduziu um barquinho a meia altura que se mexia e lançava um fumo pequenino e pouco mais), o espectáculo foi um testemunho vivo de uma arte pensada e realizada com saber, inventividade e um enorme rigor. 0 que dava vivo e eloquente testemunho da legitimidade do Prémio Europa para o Teatro que o júri atribuíra ao seu carismático encenador - Peter Zadek - por mais desaguisado que tivesse sido o percalço da sua formalização cerimonial. 